\title{
Bringing Society Back into the Climate Debate
}

\author{
Roger A. Pielke Jr. \\ Center for Science and Technology Policy Research, University of \\ Colorado \\ Daniel Sarewitz \\ Center for Science, Policy, and Outcomes, Arizona State University
}

Debate over climate change focuses narrowly on the reduction of greenhouse gas emissions. A common justification for such emissions reductions is that they will lead to a reduction in the future impacts of climate on society. But research from social scientists and others who study environment-society interactions clearly indicates that the dominant factors shaping the impacts of climate on society are societal. A greater appreciation for this body of research would allow for consideration of a broader base of policy options to respond to the challenges of climate change, as well as the composition of climate research portfolios more likely to contribute useful knowledge to decision makers.

KEYWORDS: climate change; policy; disasters; extreme events; demographics.

The issue of climate change has been mired in strident political conflict since the mid-1980s. The conflict takes the form of public debate over whether or not and to what extent human emissions of greenhouse gases (most notably carbon dioxide) may lead to changes in future climatic conditions. The debate takes place in the language of science, but is really

Please address correspondence to Roger A. Pielke, Jr., Center for Science and Technology Policy Research, University of Colorado; e-mail: pielke@colorado.edu

Daniel Sarewitz, Center for Science, Policy, and Outcomes, Arizona State University; e-mail: dsarewitz@asu.edu 
about political positions for and against regulations of greenhouse gases, such as proposed under the Kyoto Protocol on climate change (Sarewitz \& Pielke, 2000). But two well documented aspects of the climate-society relationship are largely absent from the climate debate: (1) the awareness that, over time, societal changes-demographic, social, economic, and other changes in the characteristics of human populations-are primary factors in climatic impacts on humans and human impacts on the environment; and (2) viable strategies for responding to such changes lie predominantly in the area of societal governance, not in efforts to control the future behavior of climate.

Such findings are well-supported in the academic literature and are probably not news to many social scientists and others who study environment-society interactions. For example, Rayner and Malone's (1998) comprehensive four-volume work Human Choice and Climate Change concludes with "ten suggestions for policymakers" (p. 109), all of which are aimed at providing alternatives to the belief that emissions reductions are the appropriate core strategy for coping with climatic and societal changes. It is time for such understandings to occupy a more central role in debate over climate change, in the development of practical and effective policy options for responding to climate variability and change, and in conducting research that supports the information needs of policy makers (For additional examples of scholarship and recommendations along these lines, see Brunner, 2001; Byerly, 1989; Kabat et al., 2003; Laird, 2001; Lempert \& Schlesinger, 2000; NRC, 1999; NRC 2003; OTA, 1993; Vörösmarty, Green, Salisbury, \& Lammers, 2000).

If such perspectives played a more prominent role in the climate debate they would likely highlight a well-known phenomenon among those who study the societal and economic impacts of weather and climate: these impacts have been growing continuously for at least the past century (e.g., IFRC, 2003). The primary cause for the growth in impacts is the increasing vulnerability of human and environmental systems to climate variability and change, not changes in climate per se. To address increasing vulnerability, and the growing impacts that result, requires that we consider adaptation to climate to be as important as matters of energy policy in discussion of response options. The climate debate has only recently reflected a turn towards adaptation. Increased attention to adaptation would not mean that we should ignore energy policies, but instead represents clear-eyed recognition that changes in energy policy are insufficient to address the primary factors underlying trends in the societal impacts of weather and climate. With such a perspective the nation's investments in research to support policy making could be more efficiently focused on producing 


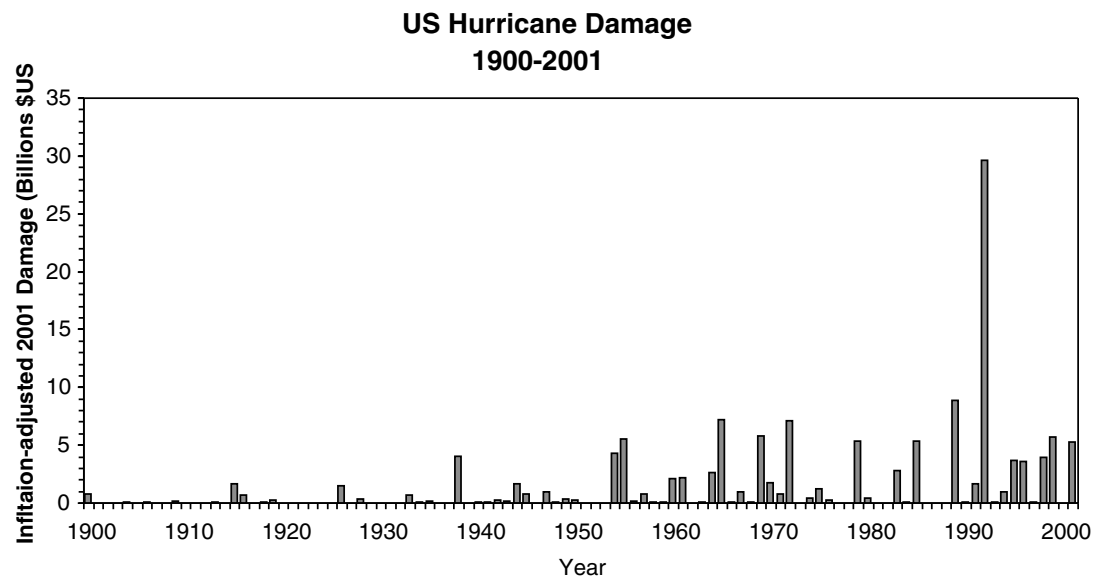

FIGURE 1. U.S. hurricane damage 1900-2001, adjusted for inflation to 2001 values.

usable information for decision makers seeking to reduce vulnerabilities to climate. Specifically, the present research agenda is improperly focused on prediction of the distant climate future (Pielke \& Sarewitz, 2003). This Policy View develops these points through a case study focused on tropical cyclones.

Policy debate and advocacy on the issue of climate change frequently focus on the potential future impacts of climate on society, usually expressed as economic damage or other human outcomes. But it is well understood that societal impacts of climate are a joint result of climate phenomena (e.g., hurricanes, floods, and other extremes) and societal vulnerability to those phenomena (e.g., Mileti, 1999). Yet in the climate change debate, political advocates often point in extreme weather events (e.g., hurricanes, floods, and winter storms) as a potentially serious consequence of climate change for humans around the world, and then link such increases to a need to take particular political actions. For instance, in October, 2004 a group of scientists at Harvard and the National Center for Atmospheric Research held a press conference to argue that the very active 2004 hurricane season supported efforts to regulate greenhouse gases (O'Brien, 2004). And an advocacy group called Scientists and Engineers for Change opposed the election of George Bush in 2004 by posting billboards in Florida with the message: "Global Warming = Worse Hurricanes. George Bush Just Doesn't Get It" (http://www.environment2004.org/ story.php?id=596). 


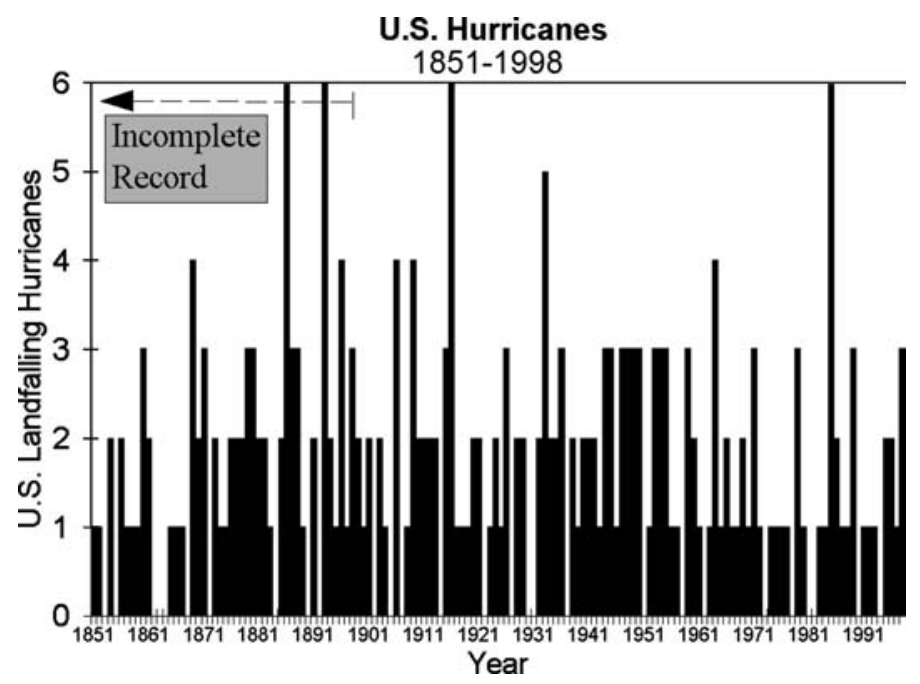

FIGURE 2. U.S. hurricane landfalls, 1851-1998, figure courtesy of C. Landsea.

But research into the societal impacts of extreme events repeatedly shows that societal vulnerability is the single most important factor in the growing damage related to extreme events (e.g., Kunkel, Pielke, \& Changnon, 1999). An implication of this research for policy is that decision making at local levels (e.g., related to land use, insurance, building codes, warning and evacuation) can have a profound effect on the magnitude and significance of future damage, much more in fact than can efforts to modulate the incidence of extreme events via energy policies.

Consider the case of tropical cyclone impacts (the following case study is developed in detail in Pielke, Klein \& Sarewitz, 2000). Fig. 1 shows economic damage (adjusted for inflation) related to hurricane landfalls in the United States, 1900-2001 (updated from Pielke \& Landsea, 1999). Although damage is growing in both frequency and intensity, this trend does not reflect increased frequency or strength of hurricanes. In fact, while hurricane frequencies have varied a great deal over the past $100+$ years, they have not increased in recent decades in parallel with increasing damages (Fig. 2, provided courtesy of C. Landsea et al., NOAA, cf. Landsea et al., Pielke, Mestas-Nuñez, \& Knaff, 1999). To the contrary, although damage increased during the 1970s and 1980s, hurricane activity was considerably lower than in previous decades. 


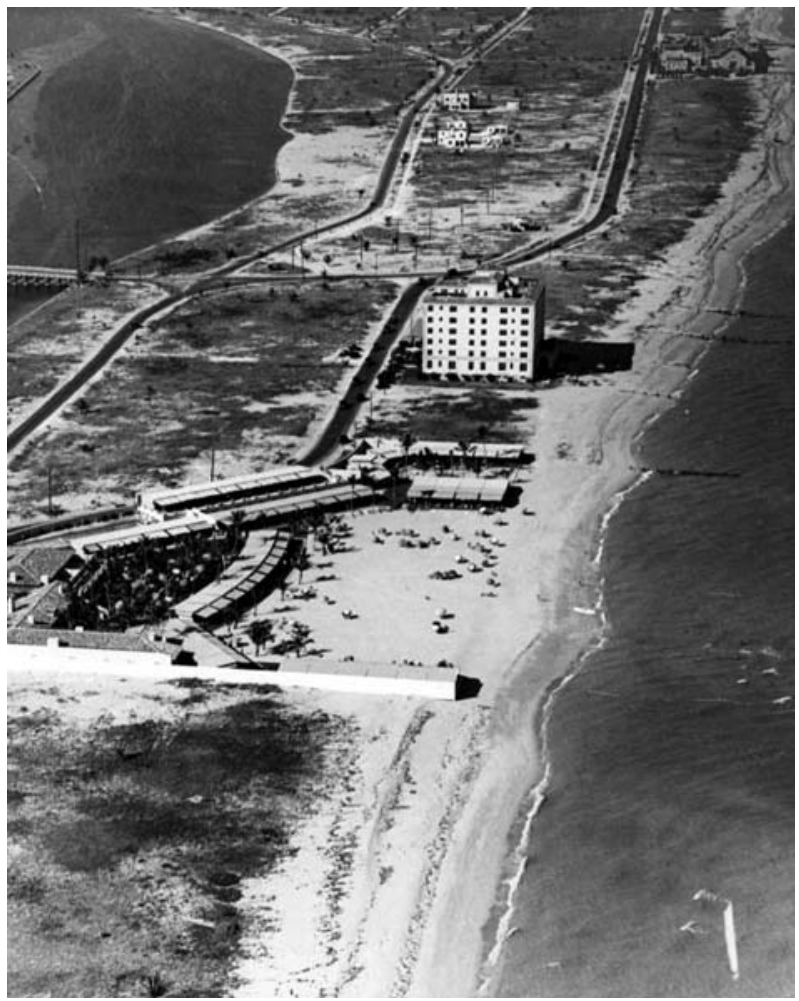

FIGURE 3a. Miami Beach, 1926. Photo from the Wendler Collection, Florida State Archives. Used with permission.

To explain the increase in damage it is therefore necessary to consider factors other than variability or change in climate. In particular, society has changed enormously during the period covered by Figure 2. Figure 3a and b show this dramatically. Fig. 3a shows a stretch of Miami Beach in 1926. Figure $3 b$ shows another perspective of Miami Beach from recent years. The reason for increasing damages is apparent from the changes easily observable in these figures: today there is more potential for economic damage than in the past due to population growth and increased wealth (e.g., personal property).

Fig. $4 \mathrm{a}$ and $4 \mathrm{~b}$ shows the increase in population along the Gulf and Atlantic coasts for 168 coastal counties from Texas through Maine (Figure 4a). In 1990, the population of Miami and Ft. Lauderdale (2 counties) 


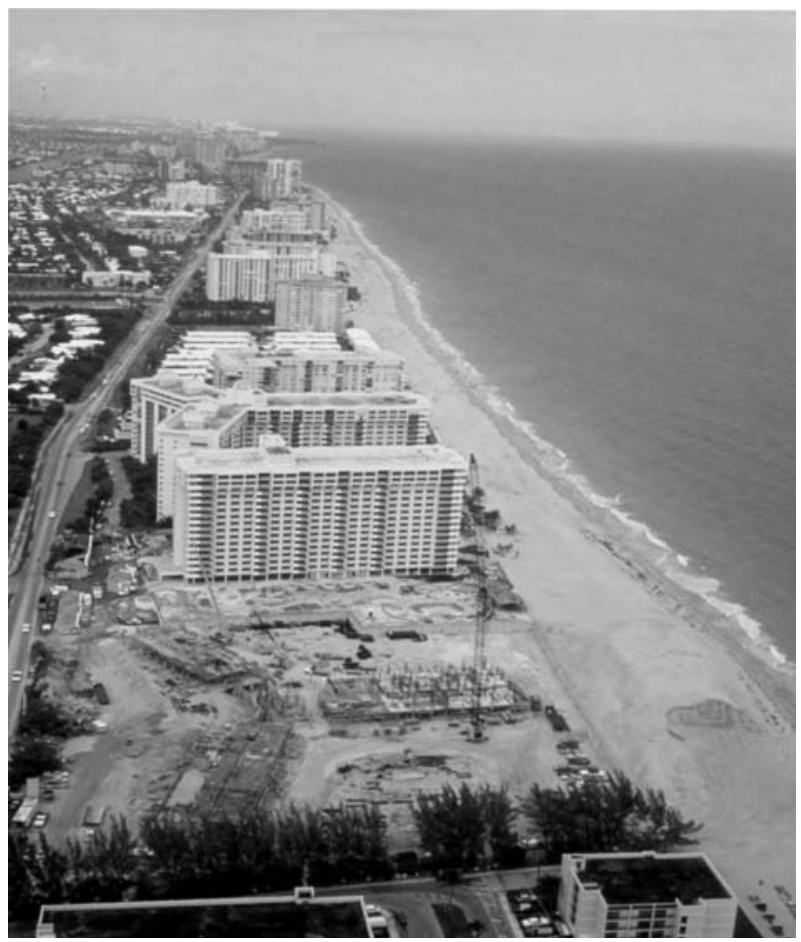

FIGURE 3b. Miami Beach, recent decades. Undated photo from the NOAA Arcive.

exceeded the combined population of 107 counties from Texas to Virginia (Pielke \& Pielke, 1997). Clearly, societal changes such as coastal population growth have had a profound effect on the frequency and magnitude of impacts from weather events such as hurricanes.

Given the significance of societal change in trends of hurricane damage, one way to present a more accurate perspective on such trends is to consider how past storms would affect present society. Pielke and Landsea (1998) presented a methodology for "normalizing" past hurricane damage to present day values (using wealth, population and inflation). Fig. 5 shows the historical losses of Figure 1 normalized to 2001 values. The normalized record shows that the impacts of Hurricane Andrew, at close to $\$ 40$ billion (2001 values), would have been far surpassed by the Great Miami Hurricane of 1926, which would cause an estimated $\$ 93$ billion damage had it occurred in 2001. We can have confidence that the 


\section{U.S. Atlantic and Gulf Coastal Counties}

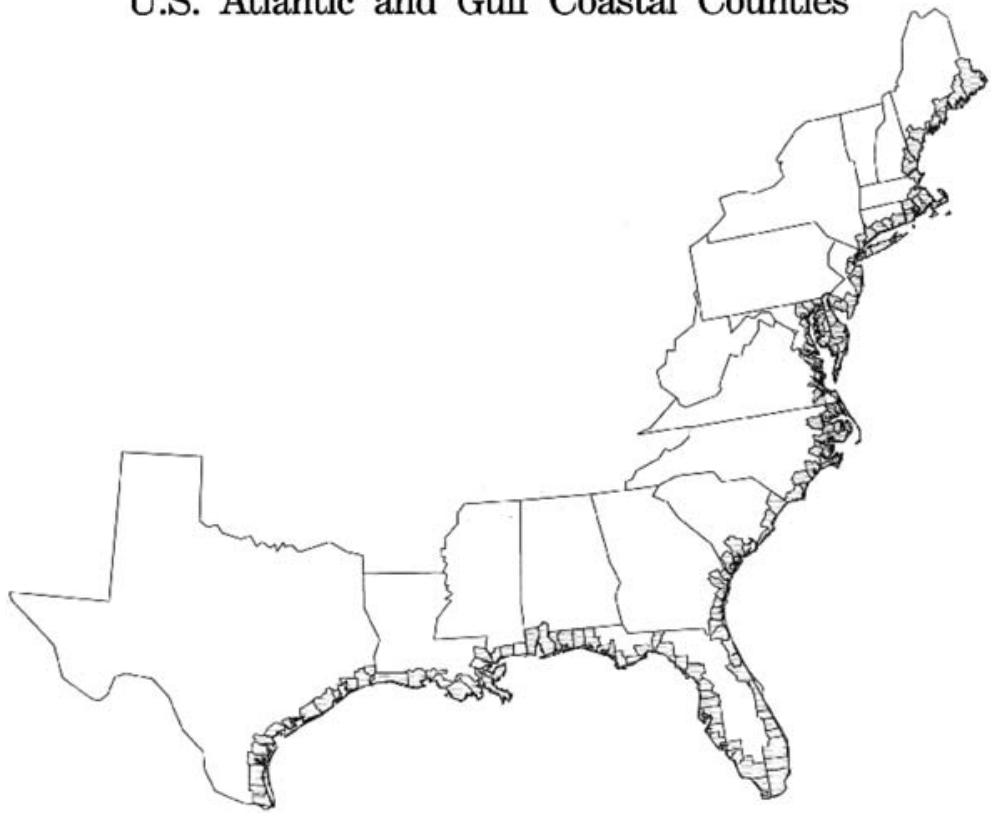

FIGURE 4a. Map of 168 coastal counties from Texas through Maine.

normalized loss record accounts for societal changes because, unlike the unadjusted data, the adjusted damage data accurately reflect well-understood patterns of climate variability, such as the signal of El Niño and La Niña in hurricane frequencies (Pielke \& Landsea, 1999).

The normalization methodology provided an opportunity to perform a sensitivity analysis of the relative contributions of climate changes and societal changes, as projected by the Intergovernmental Panel on Climate Change (IPCC), to future topical cyclone damages. Fig. 6 shows the results of this analysis. The three blue bars show three different calculations (named for their respective authors) used by IPCC in its Second Assessment Report for the sensitivity of tropical cyclone-related damage in 2050 (relative to 2000) resulting from changes in the climate, independent of any changes in society. The four green bars show the sensitivity of tropical cyclone-related damage in 2050 (relative to 2000) resulting from changes in society based on four different IPCC population and wealth scenarios used in its Third Assessment Report. These changes are independent of any changes in climate. 
POPULATION BY COASTAL COUNTY
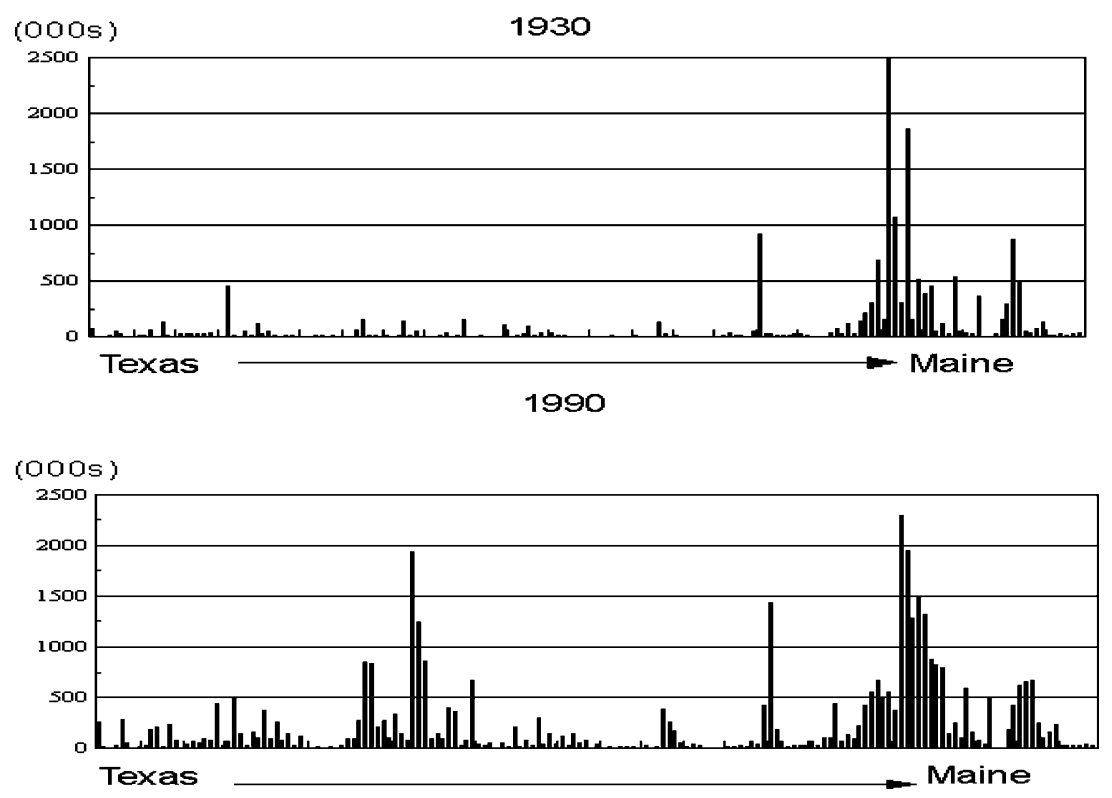

FIGURE 4b. Population of the 168 coastal counties from Texas through Maine for 1930 and 1990 based on U.S. Census data.

Figure 6 illustrates dramatically the profound sensitivity of future climate impacts to societal change, in the context of climate and societal changes projected by the IPCC. In terms of total damage, the relative sensitivity of societal change to climate change ranges from 22 to 1 (i.e., smallest societal sensitivity and largest climate sensitivity) to 60 to 1 (i.e., largest societal sensitivity and smallest climate sensitivity). This indicates that insofar as tropical cyclones are concerned, under the assumptions of the IPCC steps taken to modulate the future climate (e.g., via greenhouse gas emissions or other energy policies) can only address a very small portion of the increasing damages caused by tropical cyclones.

A recent exchange in Science magazine reported similar results in the context of malaria, another condition often cited as a primary reason for concern about climate change. In the exchange between Indur M. Goklany, of the Office of Policy Analysis, U.S. Department of the Interior and Sir David A. King, Chief Scientific Adviser to U.K Prime Minister Tony Blair and Head of the Office of Science and Technology, Goklany (2004) writes that King (2004) justifies action to mitigate climate change based on the 


\section{Annual Hurricane Damage: 1900 - 2001} Normalized to 2001 Values

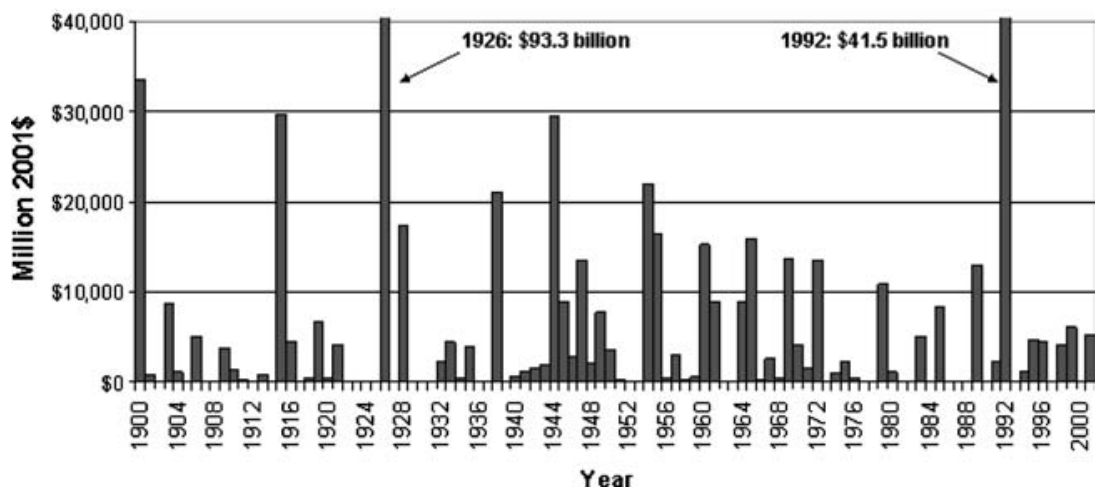

FIGURE 5. Historical losses from hurricanes adjusted to 2001 values based on inflation, population, and wealth. The graph suggests the damage that would have occurred had storms of past years made landfall with the societal conditions of 2001.

argument that because "of continued warming, millions more people around the world may in future be exposed to the risk of hunger, drought, flooding, and debilitating diseases such as malaria. Poor people in developing countries are likely to be most vulnerable." Goklany's response places climatic factors into their broader context:

... the population at risk of malaria (PAR-M) in the absence of climate change is projected to double between 1990 and the 2080 s, to 8,820 million. However, unmitigated climate change would, by the 2080s, further increase PAR-M by another 257323 million. Thus, by the 2080s, halting further climate change would, at best, reduce total PAR-M by $3.5 \%[=100 \times 323 /$ $(323+8,820)]$. On the other hand, reducing carbon dioxide emissions with the goal of eventually stabilizing carbon dioxide at $550 \mathrm{ppm}$ would reduce total PAR-M by $2.8 \%$ at a cost to developed nations, according to King, of $1 \%$ of GDP in 2050, or about $\$ 280$ billion in today's terms. But malaria's current annual death toll of about 1 million could be halved at an annual cost of $\$ 1.25$ billion or less, according to the World Health Organization, through a combination of measures such as residual home spraying with insecticides, insecticide-treated bednets, improved case management, and more comprehensive antenatal care. 


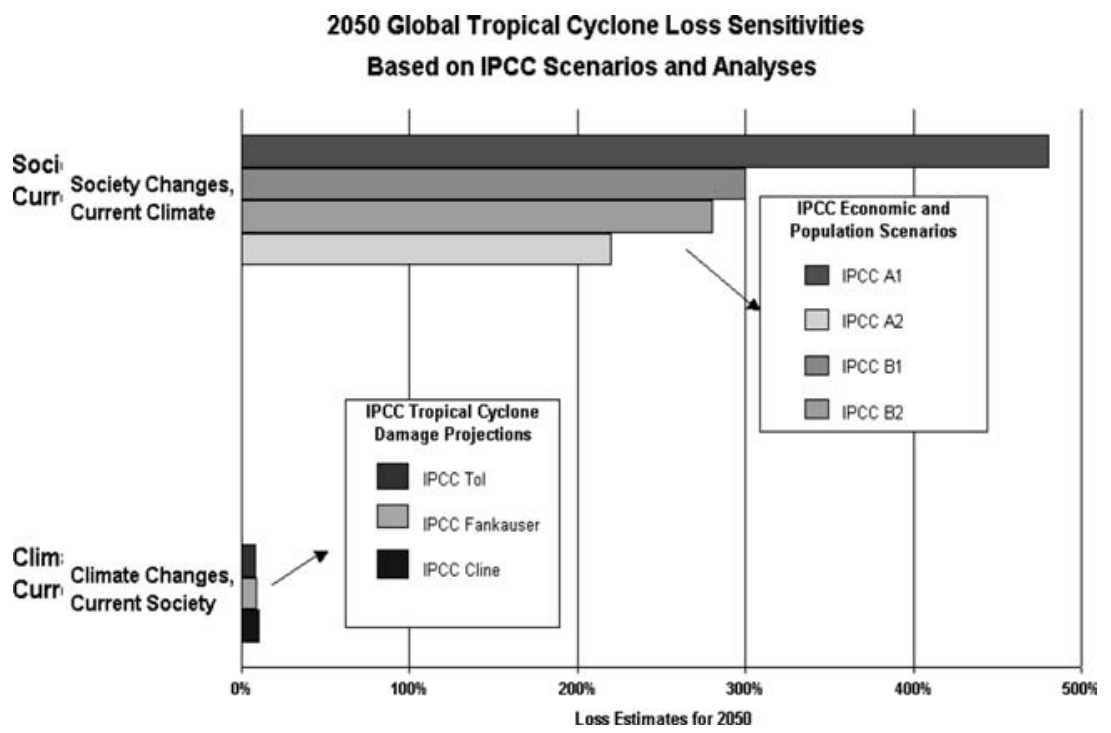

FIGURE 6. A sensitivity analysis of the impacts of tropical cyclones in 2050 based on the assumptions of the Intergovernmental Panel on Climate Change. The green bars show sensitivity of future impacts to societal changes and the blue bars show sensitivity to climate changes. Societal changes are the overwhelmingly dominant factor.

Clearly, implementing such measures now would provide greater malaria benefits over the next few decades than would climate stabilization at any level. It would also reduce vulnerability to malaria from all causes-man-made or natural-now and in the future.

King's response to Goklany simply avoids the issue:

There is no real choice between action on climate change and action on poverty, disease, hunger, and other millennium development goals. These are part of the same sustainable development agenda. Climate change is already affecting developing countries, and it is the poorest regions of the world — such as Africa and Southeast Asia-that are most at risk. The many people who have died and the millions now homeless 
through the monsoon flooding in Bangladesh will bear witness to that. This kind of event can be expected to become more frequent and more extreme as global warming accelerates, exacerbated by rising sea levels.

Similar results highlighting the relationship of societal factors to climate factors have been found for tropical cyclone impacts in developing countries (Pielke, Rubiera, Landsea, Fernandez, \& Klein, 2003), flooding (Pielke \& Downton, 2000), other extremes (Kunkel, Pielke, \& Changnon, 1999), and water resources (Vörösmarty et al., 2000).

Highlighting the central role played by the characteristics of population and society in shaping future climate impacts is not to diminish the importance of climate change as an issue worth addressing. Nor does it diminish other justifications for climate mitigation. But it does raise questions about whether justifying action on energy policy based on addressing the future impacts of extreme events can in fact lead to their intended effects, and whether other, perhaps more practical and empirically grounded policies are being overlooked in the process. The leading science and policy institutions on climate change have arguably underplayed issues of population and development as factors shaping future climate-related impacts.

To better understand how research portfolios in climate meet the information needs of decision makers, in collaboration with a diverse team of researchers, we have recently been awarded a major National Science Foundation grant ("Science Policy Assessment and Research on Climate") that includes a focus on "sensitivity analysis" in order to better disaggregate the various factors that may contribute to future climate-related impacts. The ultimate goal of such research is to provide information that helps decision makers better focus finite resources available for scientific research on those areas most likely to contribute useful knowledge for climate policy makers.

One obstacle to realizing a greater focus on society and population in the climate issue lies with how the Framework Convention on Climate Change (FCCC) defines "climate change" in a way that largely excludes considerations of the role of societal change as a factor influencing climate impacts on humans and the environment (Pielke, 2004). Under the FCCC the term "climate change" is defined as "a change of climate which is attributed directly or indirectly to human activity that alters the composition of the global atmosphere and which is in addition to natural climate vari- 
ability over comparable time periods." This definition stands in stark contrast to the broader definition used by the Intergovernmental Panel on Climate Change (IPCC) which states that climate change is "any change in climate over time whether due to natural variability or as a result of human activity."

As a consequence of the FCCC definition, "adaptation" refers to actions in response to climate changes attributable solely to greenhouse gas emissions. It does not refer to efforts to improve societal responses to climate impacts related to "natural" climate variability or population growth. Consequently, adaptation has only "costs" because adaptive responses would by definition be unnecessary if climate change could be prevented. Hence, under this particular framing of the issue it is logical for many to conclude that "preventative" action is a better policy alternative and recommend adaptive responses only to the extent that proposed mitigation strategies will be unable to prevent changes in climate in the near future. But this overlooks the fact that even if energy policy could be used intentionally to modulate and control future climate, other factors will play a much larger role in creating future impacts and are arguably more amenable to policy change.

As Figure 6 shows dramatically, an increased focus on "adaptation" makes sense under any climate scenario. But the Framework Convention is structured formally to deal only with the growth in impacts related to the greenhouse gas impacts on the climate (the blue bars) and not the profound societal vulnerability (green bars) that will dominate future climate impacts under any climate change scenario.

Consider that the International Red Cross estimates that in the 1990s around the world, weather and climate events were directly related to more than 300,000 deaths and more than US\$700 billion in damages (IFRC, 2000). Many of these human losses are preventable and economic losses are manageable with today's knowledge and technologies (there is a very large literature on this topic, see, e.g., Mileti, 1999). Simple steps taken to reduce societal vulnerability to weather and climate could also make society more resilient to future variability and change. Moreover, society has experience in successfully taking such steps, whereas it has no successful experience in consciously modifying global climate to yield desired societal outcomes. Seen from this perspective, costs of adaptation would easily be exceeded by the benefits of better dealing with the impacts of climate, irrespective of future changes in climate and their causes. The Framework Convention's definitional gerrymandering of "climate change" according to attribution prejudices policy and advocacy against such common sense activities. 


\section{TOWARD A MORE COMPREHENSIVE VIEW OF CLIMATE AND ENERGY POLICIES}

Policy related to societal impacts of climate has important and underappreciated dimensions that are independent of energy policy. It would be a misinterpretation of the meaning of our work to suggest that it supports business-as-usual energy policies, or obviates climate mitigation. But if a policy goal is to reduce the future impacts of climate on society, then energy policies are insufficient, and perhaps largely irrelevant, to achieving that goal. Of course, this does not preclude other sensible reasons for energy policy action related to climate (e.g., abrupt climate change) and energy policy action independent of climate change (such as national security, air pollution reduction and energy efficiency). It does suggest that reduction of human impacts related to weather and climate are not primary among those reasons, and arguments and advocacy to the contrary are not in concert with research in this area.

Governments and businesses are already heavily invested in climate policy and thus should focus resources on decisions likely to be effective with respect to policy goals. In the context of extreme events, such decisions might focus increasingly on land use, insurance, engineering, warnings and forecasts, risk assessments, and so on. These policies can make a large difference in mitigating the future impacts of climate on society. Focusing more attention on the integrated, multidisciplinary aspects of climate impacts will likely show that current research portfolios that are focused on long-term predictions of the climate future are out of balance with respect to the information needs of decision makers. We are embarking on a project that hopes to produce information that will help to identify such mismatches and recommend a range of options for climate science policy better suited to meeting the needs of decision makers.

\section{REFERENCES}

Brunner, R. (2001). Science and the climate change regime. Policy Sciences, 34(1), 1-33. Byerly, R. Jr. (1989). The policy dynamics of global change. Earthquest, 3(1), 11-13.

Goklany, I. (2004). Climate change and malaria. Science, 306, 55-57.

International Federation of Red Cross and Red Crescent Societies (IFRC), 2003.World Disasters Report, www.ifrc.org.

Kabat, P., Claussen, M., Diremeyer, P. A., Gash, J. H. C., Deguenni, L. B., Meybeck, M., Pielke, Sr., R. A., Vörösmarty, C. J., Hutjes, R. W. A., \& Lütkemeier, S. (Eds.) (2003). Vegetation, Water, Humans and the Climate: A New Perspective on an Interactive System. Synthesis of the ICBP Core Project, Biospheric Aspects of the Hydrologic Cycle, Global Change, The IGBP Series, Springer, 650 pp. 
POPULATION AND ENVIRONMENT

King, D. (2004). Climate change and malaria. Science, 306, 55-57.

Kunkel, K., Pielke, R. A. Jr., \& Changnon, S. A. (1999). Temporal fluctuations in weather and climate extremes that cause economic and human health impacts: A review. Bulletin of the American Meteorological Society, 80(6), 1077-1098.

Laird, F. (2001). Just say no to emissions reductions targets. Issues in Science and Technology, Winter.

Landsea, C. L., Pielke, R. A. Jr., Mestas-Nuñez, A., \& Knaff, J. (1999). Atlantic basin hurricanes: Indicies of climate changes. Climatic Change, 42, 89-129.

Lempert, R. J., \& Schlesinger, E. (2000). Robust strategies for abating climate change. Climatic Change, 45(3-4), 387-401.

Mileti, D. (1999). Disasters by Design. Joseph Henry Press.

Mileti, D. (2000). Second Assessment of Natural Hazards. Joseph Henry Press.

NRC. (1999). Making Climate Forecasts Matter. In Paul C. Stern \& William E. Easterling (Eds.), Panel on the Human Dimensions of Seasonal-to-Interannual Climate Variability; Committee on the Human Dimensions of Global Change National Research Council, Washington, DC: National Academy Press.

NRC. (2003). Planning Climate and Global Change Research: A Review of the Draft U.S. Climate Change Science Program Strategic Plan. National Research Council, Washington, DC: National Academy Press 84.

O'Brien, D. (2004). A storm over global warming: Some link temperature to '04 hurricanes. The Seattle Times, 7 November.

OTA. (1993). Preparing for an Uncertain Climate, Office of Technology Assessment, United States Congress, Vol. 1, OTA-0-567.

Pielke, R. A. Jr. (2004). What is climate change?, Issues in Science and Technology, Summer, $1-4$.

Pielke, R. A. Jr., \& Downton, M. W. (2000). Precipitation and damaging floods: Trends in the United States, 1932-1997. Journal of Climate, 13, 3625-3637.

Pielke, R. A. Jr., Klein, R. A., \& Sarewitz, D. (2000). Turning the big knob: Energy Policy as a Means to Reduce Weather Impacts. Energy and Environment, 11(3), 255-276.

Pielke, R. A. Jr., \& Landsea, C. W. (1998). Normalized hurricane damages in the United States: 1925-1995. Weather and Forecasting, 13, 351-361.

Pielke, R. A. Jr., \& Landsea, C. W. (1999). La Niña, El Niño, and Atlantic hurricane damages in the United States. Bulletin of the American Meteorological Society, 80, 2027-2033.

Pielke, R. A. Jr., \& Pielke, R. A. Sr. (1997). Hurricanes: Their nature and impact on Society. London: John Wiley and Sons Press.

Pielke, R. A. Jr., Rubiera, J., Landsea, C., Fernandez, M., \& Klein, R. A. (2003). Hurricane vulnerability in Latin America and the Caribbean. Natural Hazards Review, 4, 101-114.

Pielke, R. A. Jr., \& Sarewitz, D. (2003). Wanted: Scientific Leadership on Climate; Issues in Science and Technology, Winter, 27-30.

Rayner, S., \& Malone, E. L. (Eds.) (1998). Human Choice and Climate Change, Vol. 1-4. Columbus, $\mathrm{OH}$ : Battelle Press.

Sarewitz, D., \& Pielke, R. A. Jr. (2000). Breaking the Global-Warming Gridlock. The Atlantic Monthly, 286(1), 55-64.

Vörösmarty, C. J., Green, P., Salisbury, J., \& Lammers, R. B. (2000). Global water resources: Vulnerability from climate change and population growth. Science, 289, 284-288. 